\title{
In vitro Antiviral Activity of Bacopa monnieri (1.) Wettst Roots Methanolic Extract Against Dengue Virus Type 2
}

\section{Keerthy $\mathrm{M}^{1 *}$, M Arya Lakshmi ${ }^{1}$ and B Ganga Rao ${ }^{2}$}

${ }^{1}$ Pharmacognosy and Phytochemistry Research Division, University College of

Pharmaceutical Sciences, Andhra University, Andhra Pradesh, India

${ }^{2}$ Principal, KJR college of Pharmacy, Andhra Pradesh, India

*Corresponding Author: Keerthy M, Pharmacognosy and Phytochemistry Research Division, University College of Pharmaceutical Sciences, Andhra University, Andhra

Pradesh, India.
Received: August 02, 2021

Published: September 22, 2021

(C) All rights are reserved by Keerthy M.,

et al.

\begin{abstract}
Dengue is the most widely spread arthropod-transmitted viral diseases of human beings, approximately 390 million people are getting symptomatic infections annually and more than 2 billion people are living in risk conditions. Specified antiviral drug has not approved yet against dengue and in some countries restricted introduction of dengue vaccine is the only source. the only there is only limited introduction of a dengue vaccine in some countries. Bacopa monnieri (L.) Wettst plantfrequently called as Brahmi and water hyssop, belongs to the family of Plantaginaceae. Bacopa monnieri (L.) Wettst is used as a medicine to cure various conditions including infections. In this study, determination of maximum non-toxic dose (MNTD) of the Bacopa monnieri (L.) Wettst was done against Vero E6 cells under in vitro conditions with the methanolic extract. The antiviral assay of Bacopa monnieri (L.) Wettst based on cytopathic effects (CPE) represented by degree of inhibition against DENV serotype 2 strain. Results showed that Bacopa monnieri (L.) Wettst had significant anti-dengue activity in Vero E6 cell lines by lowering the levels of cellular infection as well as virus output. It is done with the $50 \%$ effective concentrations for DENV 2 for Vero E6 cell lines. These results of this study by using MTT assay method, in which the Percentage of inhibition in the presence of Bacopa monnieri methanolic extract for Anti DENV-2 activity was increased dose dependent manner from 1.56 to $100 \mu \mathrm{g}$ in DENV-2 infected cell. The results indicated that Bacopa monnieri (L.) Wettst has a potentiality as an anti-viral agent against dengue infection for further development.
\end{abstract}

Keywords: Dengue Virus DENV 2; Bacopa monnieri (L.) Wettst; Plantaginaceae; Antiviral

Dengue is a mosquito-borne viral infection, found in tropical and sub-tropical climates worldwide, mostly in urban and semi-urban areas. The incidence of dengue has grown dramatically around the world in recent decades. A huge majority of cases are asymptomatic or mild and therefore the true dengue cases are under-reported. Numerous cases are also misidentified as other febrile illnesses [1]. Some studies revealed approximately 390 million dengue virus infections are observing annually, out of which 96 million have distinct symptoms clinically [2]. Another study on the ubiquity of dengue infection is about 3.9 billion people are at a risk of infection with dengue viruses. In spite of a risk of infection surviving in 129 countries [3], the real implication occurred about 70\% in Asia [2]. According to WHO the dengue cases have raised over 8 folds over the last 2 decades. Deaths happened due to dengue infections have raised from 960 to 4032 between the year 2000 and 2015 [3]. Presently, there is no particular treatment for dengue infection. However, significant medical treatment could save the patient's 
lives [4]. Clinical manifestations of dengue infection ranges from asymptomatic: Dengue Fever (DF), Dengue Hemorrhagic Fever (DHF), eventually Dengue Shock Syndrome (DSS) [5]. The preventive measures for diminishing of the dengue infection are mostly vector control and suggested dengue vaccine [6]. Research says that particular dengue vaccine shows some promising effect to prevent severe dengue cases although further study is required [4]. For the development of a novel anti-viral agent invitro model experiments are using which is a main issue. The cell substrate requirements for virus replication restricting the screening of novel compounds. Due to this reason, only a few drugs have raised as efficient antiviral drugs [7]. Alternatively, to develop a novel anti-viral drug for dengue various medicinal plant extracts are going to be investigate [8]. Few phytochemical compounds such as flavonoid, phenolics, and terpenoid which would be extracted from natural products were suggested to have an antiviral activity against dengue [9,10]. Bacopa monnieri (L.) Wettst plant frequently called as Brahmi and water hyssop, belongs to the family Plantaginaceae. It is used traditionally in Asia to treat malaria, headache, diarrheal infections and for the memory enhancement [11-13]. Two most important flavonoids include luteolin and apigenin were identified in Bacopa monnieri plant [14]. In this study, we move forward to evaluate the antiviral activity of Bacopa monnieri against DENV- 2 virus. The control over fever in dengue infection was done by using various synthetic types of drugs including aspirin, paracetamol. So many adverse effects are there by taking these synthetic types of drugs. Therefore, herbal medicines are used in the form of alternative therapy as they possess lesser side effects and more availability.

\section{Materials and methods}

Collection of plant material and its authentication

Roots of Bacopa monnieri (L.) Wettst plant was collected from the area of Andhra University, Visakhapatnam. The authentication was done by Dr. Padal, Taxonomist, Department of Botany, Andhra University, Andhra Pradesh. The roots were sorted out, cleaned. These roots were chopped and dried at room temperature. This can be grounded into a coarse powder.

\section{Methanol extract preparation}

The coarse powder of root material was extracted with methanol by using soxhlation process and gets filtered. By using a rotary evaporator, the extract was concentrated. The concentrated mass was placed in air tight container and kept in a desiccator for further studies.
Preparation of extract for cytotoxicity and antiviral assay

For the cytotoxicity and antiviral assays, a stock solution was prepared by dissolving $1.0 \mathrm{~g}$ of methanolic extract of Bacopa monnieri in $100 \mathrm{~mL}$ of dimethyl sulfoxide (DMSO) (Sigma Aldrich, USA). The stock solution was filter sterilised $(0.20 \mu \mathrm{m}$ pore, Minisart, Catalog No. 754004722) and further diluted with culture medium to the desired concentration for the assays. In this study Seven Concentrations ranging from $100 \mu \mathrm{g} / 0.1 \mathrm{ml}, 50 \mu \mathrm{g} / 0.1 \mathrm{ml}, 25 \mu \mathrm{g} / 0.1 \mathrm{ml}$, $12.50 \mu \mathrm{g} / 0.1 \mathrm{ml}, 6.25 \mu \mathrm{g} / 0.1 \mathrm{ml}, 3.12 \mu \mathrm{g} / 0.1 \mathrm{ml}$, and $1.56 \mu \mathrm{g} / 0.1 \mathrm{ml}$ were chosen.

\section{Preparation of medium}

Powdered Dulbecco's Modified Eagle's Medium (DMEM) (GIBCO, UK) was used in this study. A total of $3.7 \mathrm{~g}$ of sodium bicarbonate was added, dissolved with $1 \mathrm{~L}$ of ultrapure water and the $\mathrm{pH}$ of the medium was adjusted to 7.0. The medium was then filter sterilised using $0.22 \mu \mathrm{m}$ PES membrane filter (TPP, Switzerland) under vacuum condition.

\section{Cell line}

Vero E6 cell lines was procured from National Centre for Cell Sciences (NCCS), Pune, India and maintained in Dulbecco's Modified Eagle's Medium (DMEM) with 10\% v/v Foetal bovine serum (FBS), L-Glutamine, Sodium bicarbonate, HEPES (2-[4-(2-Hydroxyethyl)1-piperzinyl ethane sulphonic acid) buffer, Penicillin

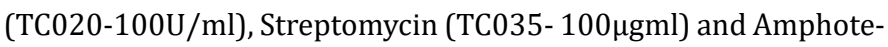
ricin-B (TC019-2.5 $\mu \mathrm{g} / \mathrm{ml})$.

\section{Maintenance and sub culturing of cells}

The cryopreserved Vero E6 cells were rapidly thawed at $37^{\circ} \mathrm{C}$ in a water bath. Cells were transferred carefully to $25 \mathrm{~cm} 2$ tissue culture flasks (Corning, USA) containing $4 \mathrm{~mL}$ of DMEM with $10 \%$ of Fetal Bovine Serum (FBS) (GIBCO, South America). Cells were then incubated at $37^{\circ} \mathrm{C}$ with $5 \%$ CO2 for 2 to 3 days until confluent. At $80-100 \%$ confluency, the cells were subcultured. The subculturing process was initiated by removing the used medium followed by rinsing the cells twice with Phosphate buffer solution (PBS) (MP Biomedical, France). Then, $1 \mathrm{~mL}$ of $0.25 \%$ trypsin-EDTA (GIBCO, Canada) was added and incubated for 5 to 10 minutes at $37^{\circ} \mathrm{C}$. After trypsinisation, $1 \mathrm{~mL}$ of fresh medium with $10 \%$ FBS was added and mixed. The mixture was then centrifuged for 10 minutes at $1500 \mathrm{rpm}$. The supernatant was discarded while the pellet was resuspended with $2 \mathrm{~mL}$ of fresh medium and re-distributed into new tissue culture flask for further maintenance. 


\section{Counting of cells}

The cells were counted using a hemocytometer. The cell suspension was mixed gently and an aliquot to the trypan blue solution was added (100ul cell suspension: 100 ul dye). The sample was mixed thoroughly and was pipetted into the junction between the counting chamber and the cover slip of hemocytometer. It was observed under light microscope. The viable and nonviable cells in both halves of the chamber were calculated.

In vitro cytotoxicity assay by MTT method

MTT (3-(4, 5-dimethylthiazol-2-yl)-2,5-diphenyl tetrazolium bromide (Himedia catalog no.TC191) was dissolved in PBS at $5 \mathrm{mg} /$ $\mathrm{ml}$ and filtered to remove insoluble particles of MTT. After the incubation period, $20 \mu \mathrm{l}$ of MTT solution was added to all wells and plates were incubated at $37^{\circ} \mathrm{C}$ at $5 \% \mathrm{CO} 2$ atmosphere for 4 hours After 4 hours, $100 \mu \mathrm{l}$ of DMSO was added to wells and incubated for 10 minutes. The plates were read on a Microplate reader, using a test wavelength of $540 \mathrm{~nm}$ [15].

\section{Antiviral assay}

DENV serotype 2 strain New Guinea C (NGC)

DENV-2 (M29095) strain was procured from National Institute of Virology (NIV) maintained in Virus Transport Medium (VTM) at $4^{\circ} \mathrm{C} .0 .1 \mathrm{ml}$ of the VTM supernatant and maintenance medium was transferred on to the monolayer of DENV-2 cell line and incubated at $37^{\circ} \mathrm{C}$ for 96 hours. Complete cytopathic effect (CPE) in DENV-2 cell line was observed on the $4^{\text {th }}$ day.

\section{In vitro antiviral assay by MTT method}

$20 \mu \mathrm{l}$ of MTT solution [3-(4,5-dimethylthiazol-2-yl)-2,5-diphenyl-2H-tetrazolium bromide] was added to all the wells. Plates were incubated at $37^{\circ} \mathrm{C}$ at $5 \% \mathrm{CO} 2$ atmosphere for 4 hours. After 4 hours $100 \mu \mathrm{l}$ of DMSO was added to wells and incubated for 10 minutes. At a wavelength of $540 \mathrm{~nm}$ the plates were read by using a Microplate reader. A gross absence of cytopathic effect was inferred by intact of cell layer, without distortion in the morphology of cells or nucleus and syncytial cells in comparison with the control rows. Hence wells with or without CPE were marked. Through Inverted Tissue Culture Microscope, an important observation of the incubated wells, both experimental and control were recorded by microphotography. The fifty percentage of inhibitory effect will be considered for antiviral study.

\section{Statistical analysis}

The in vitro cytotoxicity and antiviral activity of selected plant extracts was assessed by statistical analysis data comprising standard mean and standard deviation. P values were calculated using Graph Pad Prism 7 and graph was plotted based on the values.

\section{Results and Discussion}

In vitro cytotoxicity assay

The evaluation of cytotoxic potential of methanol extract of selected plants was investigated using the MTT assay.

In vitro cytotoxicity assay for methanol extract of Bacopa monnieri

The methanol extract of Bacopa monnieri was found to be toxic free from concentrations of $1.56 \mu \mathrm{g} / 0.1 \mathrm{ml}$ to $25 \mu \mathrm{g} / 0.1 \mathrm{ml}$ and concentrations of 50 and $100 \mu \mathrm{g} / 0.1 \mathrm{ml}$ were found to toxic in the Vero E6 cell line (Table 1). The triplicate optical density values of the MTT assay was represented in table 2. Statistical analysis and graphical representation of cytotoxicity of methanol extract of $\mathrm{Ba}$ copa monnieri showed that at $25 \mu \mathrm{g} / 0.1 \mathrm{ml}$ concentration found to be highly significant (Table 3 and Figure 1). The percentage of cell viability varied from $99 \%$ to $78 \%$ (Figure 2), thus it is proposed that there is no remarkable cytotoxic activity effect on the Vero E6 cell lines upto $50 \mu \mathrm{g} / 0.1 \mathrm{ml}$ represented (Table 4).

\begin{tabular}{|c|c|c|c|}
\hline \multirow[b]{2}{*}{ S. No } & \multirow{2}{*}{$\begin{array}{c}\text { Concentrations } \\
(\mu \mathrm{g} / 0.1 \mathrm{ml})\end{array}$} & \multicolumn{2}{|c|}{ Cytotoxicity } \\
\hline & & $\begin{array}{c}\text { Bacopa } \\
\text { monnieri }\end{array}$ & Cell control \\
\hline 1. & 1.56 & - & - \\
\hline 2. & 3.12 & - & - \\
\hline 3. & 6.25 & - & - \\
\hline 4. & 12.5 & - & - \\
\hline 5. & 25 & - & - \\
\hline 6. & 50 & + & - \\
\hline 7. & 100 & + & - \\
\hline
\end{tabular}

Table 1: Cytotoxicity profile of methanolic extract of selected plant

$(+) \longrightarrow$ Presence of cytotoxicity

$(-) \longrightarrow$ Absence of cytotoxicity. 


\begin{tabular}{|l|c|c|c|c|c|c|}
\hline \multirow{2}{*}{$\begin{array}{l}\text { Concentrations } \\
(\boldsymbol{\mu g} / \mathbf{0 . 1 m l})\end{array}$} & \multicolumn{5}{|c|}{ Absorbance at 540nm } \\
\cline { 2 - 7 } & 1.215 & 1.213 & 1.214 & 1.226 & 1.22 & 1.226 \\
\hline 1.56 & 1.213 & 1.21 & 1.212 & 1.223 & 1.216 & 1.223 \\
\hline 3.12 & 1.208 & 1.203 & 1.206 & 1.218 & 1.211 & 1.218 \\
\hline 6.25 & 1.192 & 1.188 & 1.19 & 1.223 & 1.207 & 1.223 \\
\hline 12.5 & 1.183 & 1.18 & 1.181 & 1.214 & 1.204 & 1.214 \\
\hline 25 & 1.007 & 1.002 & 1.005 & 1.22 & 1.215 & 1.22 \\
\hline 50 & 0.949 & 0.943 & 0.945 & 1.216 & 1.206 & 1.211 \\
\hline 100 & & & & & & \\
\hline
\end{tabular}

Table 2: Cytotoxicity studies of methanolic extract of Bacopa monnieri by MTT assay.

\begin{tabular}{|l|c|c|}
\hline $\begin{array}{l}\text { Concentrations } \\
(\boldsymbol{\mu g} / \mathbf{0 . 1 m l})\end{array}$ & Bacopa monnieri & Cell control \\
\hline 1.56 & $1.214 \pm 0.0006$ & $1.224 \pm 0.002$ \\
\hline 3.12 & $1.212 \pm 0.0009$ & $1.221 \pm 0.0023$ \\
\hline 6.25 & $1.206 \pm 0.0015$ & $1.216 \pm 0.0023$ \\
\hline 12.5 & $1.19 \pm 0.0012$ & $1.218 \pm 0.0053$ \\
\hline 25 & $1.181 \pm 0.0009$ & $1.211 \pm 0.0033$ \\
\hline 50 & $1.005 \pm 0.0015$ & $1.218 \pm 0.0017$ \\
\hline 100 & $0.946 \pm 0.0018$ & $1.211 \pm 0.0029$ \\
\hline P Value & $* * *$ & $* * *$ \\
\hline
\end{tabular}

Table 3: Statistical analysis of cytotoxicity of selected methanolic extract.

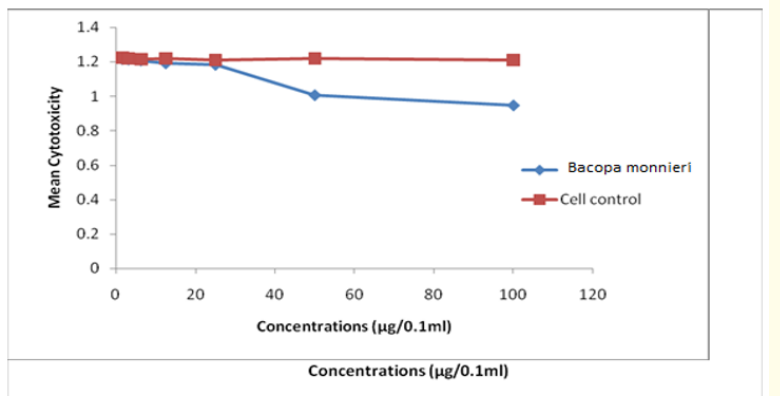

Figure 1: Cytotoxicity of selected methanolic extract of Bacopa monnieri.

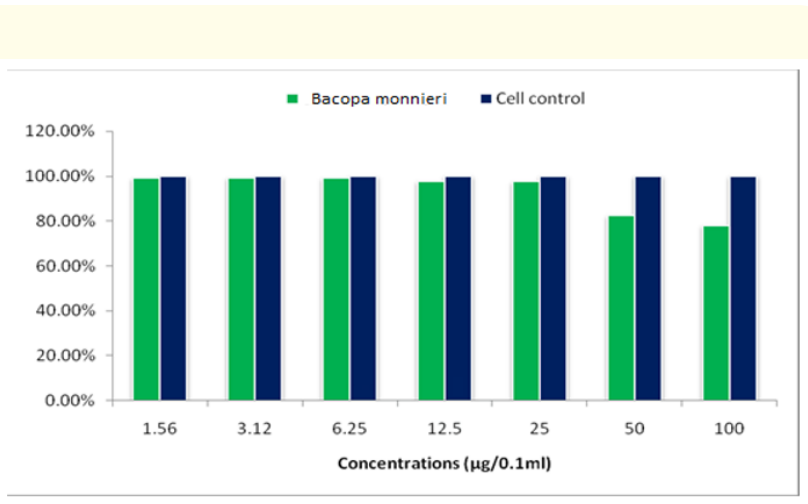

Figure 2: Percentage of viable cells in the presence of selected methanolic extract Bacopa monnieri for cytotoxicity assay.

\begin{tabular}{|l|c|c|}
\hline $\begin{array}{l}\text { Concentrations } \\
(\boldsymbol{\mu g} / \mathbf{0 . 1} \mathbf{m l})\end{array}$ & Bacopa monnieri & Cell control \\
\hline 1.56 & $99.18 \%$ & $100 \%$ \\
\hline 3.12 & $99.26 \%$ & $100 \%$ \\
\hline 6.25 & $99.18 \%$ & $100 \%$ \\
\hline 12.5 & $97.73 \%$ & $100 \%$ \\
\hline 25 & $97.58 \%$ & $100 \%$ \\
\hline 50 & $82.46 \%$ & $100 \%$ \\
\hline 100 & $78.09 \%$ & $100 \%$ \\
\hline
\end{tabular}

Table 4: Percentage of viable cells in the presence of selected methanolic extract for cytotoxicity assay.

\section{In vitro antiviral assay}

The evaluation of antiviral potential of methanol extract of selected plants was investigated using the MTT assay.

In vitro antiviral assay for methanol extract of Bacopa monnieri

In vitro anti DENV-2 activity was performed with extract of methanol from Bacopa monnieri. The methanol extract showed inhibitory activity from $50 \mu \mathrm{g} / 0.1 \mathrm{ml}$ and $12.5 \mu \mathrm{g} / 0.1 \mathrm{ml}$ concentrations (Table 5). The triplicate optical density values of MTT assay of anti DENV-2 activity was obtained (Table 6). Statistical analysis and graphical representation of antiviral activity of methanolic extract of Bacopa monnieri was represented table 7 and figure 3. The percentage of inhibition was represented table 8 and figure 4. 


\begin{tabular}{|c|c|c|c|}
\hline \multirow{2}{*}{$\begin{array}{l}\text { Concentrations } \\
(\mu \mathrm{g} / 0.1 \mathrm{ml})\end{array}$} & Cytopathic Effect & \multirow{2}{*}{$\begin{array}{c}\text { Cell } \\
\text { control }\end{array}$} & \multirow{2}{*}{$\begin{array}{c}\text { Virus } \\
\text { control }\end{array}$} \\
\hline & Bacopa monnieri & & \\
\hline 1.56 & + & - & + \\
\hline 3.12 & + & - & + \\
\hline 6.25 & + & - & + \\
\hline 12.5 & - & - & + \\
\hline 25 & - & - & + \\
\hline 50 & - & - & + \\
\hline 100 & $* *$ & - & + \\
\hline
\end{tabular}

Table 5: Antiviral activity of methanolic extract of selected plant.

$(+) \longrightarrow$ Presence of cytopathic effect

$(-) \longrightarrow$ Absence of cytopathic effect

$(* *) \longrightarrow$ Not Performed due to cytotoxicity.

\begin{tabular}{|l|c|c|c|c|c|c|}
\hline \multirow{2}{*}{$\begin{array}{l}\text { Concen- } \\
\text { trations } \\
(\boldsymbol{\mu g / 0 . 1 m l )}\end{array}$} & \multicolumn{5}{|c|}{ Absorbance at 540nm } \\
\cline { 2 - 7 } & \multicolumn{3}{|c|}{ Bacopa monnieri } & \multicolumn{3}{c|}{ Cell control } \\
\hline 1.56 & 0.198 & 0.184 & 0.271 & 1.248 & 1.246 & 1.243 \\
\hline 3.12 & 0.369 & 0.377 & 0.34 & 1.235 & 1.239 & 1.237 \\
\hline 6.25 & 0.547 & 0.568 & 0.558 & 1.247 & 1.242 & 1.245 \\
\hline 12.5 & 0.699 & 0.681 & 0.689 & 1.239 & 1.236 & 1.238 \\
\hline 25 & 0.728 & 0.725 & 0.781 & 1.234 & 1.238 & 1.248 \\
\hline 50 & $\mathrm{NP}$ & $\mathrm{NP}$ & $\mathrm{NP}$ & 1.246 & 1.246 & 1.235 \\
\hline 100 & $\mathrm{NP}$ & $\mathrm{NP}$ & $\mathrm{NP}$ & 1.248 & 1.244 & 1.248 \\
\hline
\end{tabular}

\begin{tabular}{|l|c|c|}
\hline $\begin{array}{l}\text { Concentrations } \\
(\boldsymbol{\mu g} / \mathbf{0 . 1 m l})\end{array}$ & Bacopa monnieri & Cell control \\
\hline 1.56 & $17.47 \%$ & $100 \%$ \\
\hline 3.12 & $29.26 \%$ & $100 \%$ \\
\hline 6.25 & $44.80 \%$ & $100 \%$ \\
\hline 12.5 & $55.72 \%$ & $100 \%$ \\
\hline 25 & $60.05 \%$ & $100 \%$ \\
\hline 50 & $67.35 \%$ & $100 \%$ \\
\hline 100 & Not Performed & $100 \%$ \\
\hline
\end{tabular}

Table 8: Percentage of inhibition in the presence of selected methanolic extract for Anti DENV-2 activity.

Table 6: Anti DENV-2 activity of methanolic extract of Bacopa monnieri by MTT assay.

\begin{tabular}{|l|c|c|}
\hline $\begin{array}{l}\text { Concentrations } \\
(\boldsymbol{\mu g} / \mathbf{0 . 1 m l})\end{array}$ & Bacopa monnieri & Cell control \\
\hline 1.56 & $0.218 \pm 0.0270$ & $1.246 \pm 0.0015$ \\
\hline 3.12 & $0.362 \pm 0.0113$ & $1.237 \pm 0.0012$ \\
\hline 6.25 & $0.558 \pm 0.0061$ & $1.245 \pm 0.0015$ \\
\hline 12.5 & $0.690 \pm 0.0052$ & $1.238 \pm 0.0009$ \\
\hline 25 & $0.745 \pm 0.0182$ & $1.240 \pm 0.0042$ \\
\hline 50 & Not Performed & $1.242 \pm 0.0037$ \\
\hline 100 & Not Performed & $1.247 \pm 0.0013$ \\
\hline P Value & $* * *$ & $* * *$ \\
\hline
\end{tabular}

Table 7: Statistical analysis of antiviral activity of selected methanolic extract of Bacopa monnieri.

\section{Conclusion}

The cytotoxicity as well as antiviral activity of $B$. monnieri roots extract exhibited significant $(\mathrm{p}<0.05)$ reduction in DENV-2 infe- 
cted cells and these results are compared to control. Without any cytotoxic effect the methanolic extract of Bacopa monnieri has antiviral effect against DENV-2. There is a need to study further to explore the IC50 values, CC50 values and mechanism of action regarding anti-viral activity of those plant extracts. Purification process as well as characterization of active compounds should be done furthermore to define antiviral DENV activity. The preliminary phytochemical screening of the methanolic extract of Bacopa monnieri plant has also revealed the presence of various phytocompounds such as flavonoids, alkaloids, proteins,steroids and carbohydrates. Hence, may be due to the presence of these phytochemicals the activity was possessed by this plant.

\section{Acknowledgements}

Author wish to thank to Professor Ganga Rao Battu, Principal, KJR college of Pharmacy for guiding and shows positive feedback during this work and author express her sincere thanks to the Principal of AU college of pharmaceutical sciences for the continued encouragement.

\section{Bibliography}

1. Waggoner JJ., et al. "Viremia and Clinical Presentation in Nicaraguan Patients Infected with Zika Virus, Chikungunya Virus, and Dengue Virus". Clinical Infectious Diseases 63.12 (2016): 1584-1590.

2. Bhatt, S., et al. "The global distribution and burden of dengue". Nature 496.7446 (2013): 504-507.

3. Brady OJ., et al. "Refining the global spatial limits of dengue virus transmission by evidence-based consensus". PLOS Neglected Tropical Diseases 6.8 (2012): e1760.

4. Wilder-Smith A., et al. "DengueTools: Innovative tools and strategies for the surveillance and control of dengue". Global Health Action 5 (2012): 17273.

5. Guzman MG., et al. "Secondary infection as a risk factor for dengue hemorrhagic fever/dengue shock syndrome: An historical perspective and role of antibody-dependent enhancement of infection". Archives of Virology 158 (2013): 1445-1459.

6. Badurdeen S., et al. "Sharing experiences: Towards an evidence-based model of dengue surveillance and outbreak response in Latin America and Asia". BMC Public Health 13 (2013): 607.
7. Cos P., et al. "Anti-infective potential of natural products: How to develop a stronger in vitro 'proof of concept". Journal of Ethnopharmacology 106 (2006): 290-302.

8. World Health Organization. Comprehensive Guidelines for Prevention and Control of Dengue and Dengue Haemorrhagic Fever: Revised and Expanded Edition; SEARO: New Delhi, India, (2011).

9. Ghosh A and Dar L. "Dengue vaccines: Challenges, development, current status and prospects". Indian Journal of Medical Microbiology 33 (2015): 3-15.

10. De Maio FA., et al. "The dengue virus NS5 protein intrudes in the cellular spliceosome and modulates splicing". PLoS Pathogen 12 (2016): e1005841.

11. Singh AG., et al. "An ethnobotanical survey of medicinal plants used in Terai forest of Western Nepal". Journal of Ethnobiology and Ethnomedicine 8 (2012): 19.

12. Bhowmik D., et al. "Traditional Indian memory enhancer herbs and their medicinal importance". Annals of Biological Research 1.1 (2010): 41-46.

13. Shah GM., et al. "Traditional uses of medicinal plants against malarial disease by the tribal communities of Lesser Himalayas- Pakistan". Journal Ethnopharmacology 155.1 (2014): 450462.

14. Deepak M., et al. "Quantitative determination of the major saponin mixture bacoside A in B. monnieri by HPLC". Phytochemistry Analyst 16.1 (2005): 24-29.

Volume 5 Issue 10 October 2021

(C) All rights are reserved by Keerthy M., et al. 